Hispania, 2021, vol. LXXXI, n. ${ }^{\circ}$ 269, septiembre-diciembre, págs. 713-741 ISSN: 0018-2141, e-ISSN: 1988-8368, https://doi.org/10.3989/hispania.2021.018

\title{
La Revista Nacional de Educación: «política del espíritu» y propaganda (1941-1951)*
}

\author{
Carlos Veci Lavín ${ }^{1}$ \\ Universidad de Navarra \\ cveci@alumni.unav.es
}

RESUMEN: Este artículo estudia la Revista Nacional de Educación, editada por el Ministerio de Educación Nacional entre 1941-1951, durante el mandato de José Ibáñez Martín. Este trabajo, para el que se ha consultado el archivo personal de Ibánez Martín y la colección de la revista, pone de relieve con una serie de ejemplos (la reforma universitaria, el proyecto totalitario falangista o la actividad hispanoamericanista del Ateneo de Madrid) su importancia como fuente para el conocimiento del "franquismo» y entender el papel político del Estado. La revista, cuya dirección fue encomendada a Pedro Rocamora, fue un instrumento para cumplir con la misión intelectual del Ministerio de Educación Nacional. En el ámbito ministerial, también contribuyó a su labor legislativa y a mantener informado al funcionariado del sector. En sus diez años de historia, la Revista Nacional de Educación evolucionó al compás de las funciones encomendadas a Ibáñez Martín, que supo adaptarse a las necesidades del «nuevo Estado» en la posguerra. En este sentido, la revista fue también una pieza de propaganda, atribución especialmente clave a partir de 1945, cuando las competencias de la llamada Educación Popular pasan al control de Ibáñez Martín.

\section{Palabras clave: José Ibáñez Martín; Ministerio de Educación Nacional; régimen de Franco; universidad; Falange; propaganda.}

* Siglas de archivos: Archivo General de la Universidad de Navarra, Pamplona (AGUN). De este Archivo se ha utilizado el fondo personal de José Ibáñez Martín (n. $\left.{ }^{\circ} 139\right)$.

Debo la oportunidad de escribir este artículo al programa de becas para estudiantes de doctorado de la Asociación de Amigos (AdA) de la Universidad de Navarra.

${ }^{1}$ ORCID iD: https://orcid.org/0000-0002-1436-1128

Copyright: (C) 2021 CSIC. Este es un artículo de acceso abierto distribuido bajo los términos de una licencia de uso y distribución Creative Commons Reconocimiento 4.0 Internacional (CC-BY 4.0) 
The Revista Nacional de Educación: "politics of the spirit" and propaganda (19411951)

ABSTRACT: This article studies the Revista Nacional de Educación, published by the Ministry of National Education between 1941-1951, during José Ibáñez Martin's control. This work includes information from José Ibáñez Martin's personal archive and the jorunal's collection. The objective is to highlight with examples (the university's reform, the totalitarian Falangist project and the Hispanic American activities of the Ateneo de Madrid) the significance of the journal to know Franco's regime. Furthermore, the intention of the article is to point out the journal's work for the State. The journal, directed by Pedro Rocamora, was an instrument to reach the intellectual goals of the Ministry of National Education. Moreover, the journal contributes to the legislative and informative works. During ten years, the Revista Nacional de Educación changes in order to solve the problems of postwar's "nuevo Estado". In addition, the journal was a propagandist instrument, in special since 1945, when the "Educación Popular" competences were controlled by Ibáñez Martín.

Key words: José Ibáñez Martín; Ministry of National Education; Franco's regime; University; Falange; Propaganda.

CÓMO CITAR ESTE ARTÍCULO / CITATION: Veci Lavín, Carlos, «La Revista Nacional de Educación: "política del espíritu" y propaganda (1941-1951)», Hispania, 81/269 (Madrid, 2021): 713-741. https://doi.org/10.3989/hispania.2021.018.

\section{Introducción: ¿Revista de Educación o Revista Ministerial?}

En septiembre de 1940, el ministro de Educación Nacional español, José Ibáñez Martín, nombrado un año antes, escribió una carta a personas sobresalientes del mundo de la religión, la política, la cultura y la educación con una breve petición estandarizada:

Está próxima a publicarse la REVISTA NACIONAL DE EDUCACIÓN, en la que deseo que colaboren las principales figuras de nuestro mundo científico y docente.

Entre los destinatarios había algunos del ámbito de la Iglesia, como Enrique Plá y Deniel, obispo de Salamanca, y Fernando Martín-Sánchez Juliá, presidente de la Asociación Católica Nacional de Propagandistas. Y falangistas como, por ejemplo, Pilar Primo de Rivera, Pedro Laín Entralgo y Sancho Dávila. En la correspondencia de Ibáñez Martín, depositada en el Archivo General de la Universidad de Navarra (AGUN) se conservan también cartas dirigidas a personalidades de la enseñanza. 
Los artículos debían versar sobre temas educativos. El obispo de Salamanca recibió la petición de un artículo sobre la Facultad de Teología ${ }^{2}$. Ibáñez Martín no le solicitó que escribiera sobre, por ejemplo, la misión de la Iglesia en la «nueva España». A Martín-Sánchez, quizá porque el ministro recordaba que como ingeniero agrónomo había colaborado en el periódico El Debate, le pidió un texto sobre la enseñanza agrícola ${ }^{3}$. También constan peticiones sobre estudios médicos, helenísticos y veterinarios ${ }^{4}$. Pero tampoco quería una mera revista didáctica o pedagógica, pues, cuando Celso Arévalo, catedrático del Instituto Cardenal Cisneros, le propuso colaborar con un artículo sobre «La zoología en el Arte Clásico» y le preguntó si prefería «algo de carácter más docente ${ }^{5}$, le pareció bien el tema ${ }^{6}$. Eloy Bullón, decano de la Facultad madrileña de Filosofía y Letras, recibió la petición de un artículo «sobre cualquier tema de técnica docente» ${ }^{7}$, aunque, le decía el ministro, «se admite también, un buen trabajo como suyo de Séneca o sobre tema jurídico de alguno de nuestros grandes hombres del XVI y XVII $»^{8}$. «En todo caso lo que me interesa es contar con la firma de Vd.»", escribió casi dos meses más tarde el ministro al arabista González Palencia. Desde luego, Ibáñez Martín buscaba reunir a grandes nombres. Por eso insistió a Ramón Menéndez Pidal para que escribiera un artículo sobre el Poema de Mío Cid ${ }^{10}$.

El primer plazo dado a los invitados a contribuir en la revista era demasiado breve, apenas unos días. Quizá por ello el primer número no se publicó hasta enero de 1941. La revista iba a tener una primera época de diez años, hasta que Ibáñez Martín fue relevado en el ministerio. Luego reapareció, con el nuevo título de Revista de Educación, en un número correspondiente a marzo-abril de 1952. Era ya ministro Joaquín Ruiz-Giménez ${ }^{11}$. El cuadro de colaboradores del primer número estaba formado por grandes nombres del bando vencedor en la guerra civil. Por un lado, el general Moscardó y Pilar Primo de Rivera. El defensor del Alcázar de Toledo colaboraba con un artículo sobre la educación física. La jefa nacional de la Sección Femenina disertaba sobre la formación de

\footnotetext{
2 Véase carta de Ibáñez Martín, José a Plá y Deniel, Enrique, 19/09/1940, AGUN, 139, 35.

${ }^{3}$ Véase carta de Ibáñez Martín, José a Martín-Sánchez Juliá, Fernando, 19/09/1940, AGUN, 139, 22.

${ }^{4}$ Cartas de Ibáñez Martín, José a Jiménez Díaz, Carlos, Pabón, José Manuel y Colomo, Victoriano; 19/09/1940, AGUN, 139, 18, 29 y 9.

5 Carta de Arévalo, Celso a Ibáñez Martín, José, 18/12/1940, AGUN, 139, 18.

${ }^{6}$ Véase carta de Ibáñez Martín, José a Arévalo, Celso, [sin fecha], AGUN, 139, 18.

7 Carta de Ibáñez Martín, José a Bullón, Eloy, 9/10/1940, AGUN, 139, 6.

${ }^{8}$ Carta de Ibáñez Martín, José a Bullón, Eloy, 9/10/1940, AGUN, 139, 6.

${ }_{9}$ Carta de Ibáñez Martín, José a González Palencia, Ángel, 11/12/1940, AGUN, 139, 16.

${ }^{10}$ Cartas de Ibáñez Martín, José a Menéndez Pidal, Ramón, 19/09/1940 y 21/11/1940, AGUN, 139, 23 b.

${ }^{11}$ En esta segunda etapa, la revista subraya cierta discontinuidad al comenzar de nuevo su numeración
} 
la mujer ${ }^{12}$. Ligados a la política educativa, pero también protagonistas en otros ámbitos, cabe citar a Carlos Ruiz del Castillo, Fernando Enríquez de Salamanca, el Marqués de Lozoya y Justo Pérez de Urbel. La significación ideológica de todos ellos coloreaba de tono «España nacional» a la publicación.

El primer editorial esbozaba la misión del Ministerio de Educación Nacional, que no era un cometido de segundo orden. «El choque sangriento con las hordas bárbaras ha terminado sólo en el campo de las lides militares» ${ }^{13}$, explicaba el editorial. La guerra civil había sido merecida y necesaria para purgar errores y valorar las glorias pasadas, pero ahora debía construirse el orden nuevo que demandaban la modernidad y los principios considerados auténticamente españoles. Las primeras soluciones a este problema que proponía la Revista Nacional de Educación eran la depuración, la educación en Dios y España y una legislación «de nueva planta» ${ }^{14}$, tanto en un sentido ideológico como técnico. La misión concreta que se daba a sí misma la revista era «ambiciosa y amplia $\rangle^{15}$, pero también imprecisa y, por lo tanto, abierta a una multitud de posibilidades.

Quiere ser órgano de la revolución espiritual de España; eco de sus más íntimas preocupaciones culturales; estímulo de los más oportunos progresos técnicos; difusora de las más excelentes realidades educativas dentro y fuera del país; propagadora en el extranjero de la nueva política escolar de la Falange ${ }^{16}$.

Un vistazo al primer número arroja un tono bélico e incluso azul falangista. Quizá en 1941 no podía esperarse otra respuesta a las invitaciones del ministro de Educación Nacional. Tampoco participaron aún en la revista, por los motivos que fuera, los representantes de la Iglesia. Diez años después, cuando en julio de 1951 José Ibáñez Martín fue sustituido por Joaquín Ruiz Giménez, los noventa y ocho números de la Revista Nacional de Educación constituían un buen testimonio de los avatares de su proyecto político y sus más cercanos colaboradores. El director de la revista en sus diez años de historia fue Pedro

${ }^{12}$ El ministro de Educación Nacional le pidió a Pilar Primo de Rivera un artículo «sobre la educación de la mujer al servicio del Estado» (19/09/1940, AGUN, 139, 31), petición que reiteró a mediados de octubre, pues quería que figurara en el primer número (15/10/1940, AGUN, $139,31)$. Esta insistencia prueba su intención de reunir a personajes verdaderamente significados. En noviembre le volvió a escribir rogándole que lo enviara cuanto antes o, al menos, comunicara que no iba a hacerlo, para no entorpecer las pruebas de la revista (21/11/1940, AGUN, 139, 31).

13 «Editorial», Revista Nacional de Educación, 1 (1941): 4.

${ }^{14}$ «Editorial», Revista Nacional de Educación, 1 (1941): 5.

15 «Editorial», Revista Nacional de Educación, 1 (1941): 5.

${ }^{16}$ «Editorial», Revista Nacional de Educación, 1 (1941): 5. 
Rocamora Valls, secretario político de Ibáñez Martín y jefe de las Publicaciones del Ministerio de Educación Nacional ${ }^{17}$.

La orden de creación de la revista, que tendría carácter mensual, data del 8 de marzo de $1940^{18}$. Un día antes se había creado la Oficina de Publicaciones del Ministerio de Educación Nacional ${ }^{19}$, de la que dependía. Al menos debían recibirla gratuitamente todas las escuelas. De hecho, se financiaría con las partidas destinadas a los boletines de las Secciones Provinciales de Primera Enseñanza. No obstante, estaba dirigida a todo el profesorado. Su objetivo era «imprimir unidad en el pensamiento y en el impulso a la obra educadora de la niñez y de la juventud $\gg{ }^{20}$ y divulgar los principios de la política escolar ministerial. En junio de 1942, se declaró obligatoria la suscripción a la revista para todos los centros del Ministerio de Educación Nacional ${ }^{21}$.

La historia de la Revista Nacional de Educación evidenciará que el ministerio de Ibáñez Martín fue el instrumento del Estado para desarrollar lo que uno de sus editoriales, escrito a fines de 1942, denominó «política del espíritu» ${ }^{22}$. Los editoriales de la revista, conectados con esta política, justificaron y divulgaron, a lo largo de estos diez años, los proyectos de Ibáñez Martín y su equipo. Por esta época, en plena reforma universitaria, en un momento en el que la acción estatal había colisionado con otros intereses - y derechos-, aparecieron tres editoriales que querían explicar el interés del Estado por la cultura.

El primer editorial, en octubre de 1942, trataba de la crisis de los Estados, que la revista atribuía a que habían dejado de cultivar su propia Cultura. Según el editorial, cada pueblo tenía una cultura particular ${ }^{23}$ que el Estado debía intervenir y promover si no quería morir inane. Los Estados debían desarrollar una «política del espíritu» ${ }^{24}$ que guiara, por ejemplo, a la propiamente administrativa. Pero, sobre todo, la misión de la cultura era orientativa. Servicio al Estado y no fin en sí mismo. Debía señalar objetivos o, en expresión habitual de aquel momento, «destinos» ${ }^{25}$. La revista no podía urgir más claramente a crear una

17 Véase «Nuevos rectores de la Educación Popular española», Revista Nacional de Educación, 58 (1946): 96-99. Rocamora fue nombrado el 20 de abril de 1940 [BOE, 119 (28 de abril de 1940): 2899]. Luego se hizo cargo de las Publicaciones de ministerio, ligadas al Consejo Nacional de Educación [BOE, 135 (15 de mayo de 1941): 3466], del que era vicesecretario.

18 Véase BOE, 84 (24 de marzo de 1940): 2002.

19 Véase BOE, 84 (24 de marzo de 1940): 2002.

20 BOE, 84 (24 de marzo de 1940): 2002.

${ }^{21}$ Véase BOE, 181, (30 de junio de 1942): 4678.

22 «Editorial», Revista Nacional de Educación, 23 (1942): 3-5.

${ }^{23}$ «Hay una configuración espiritual peculiar de cada unidad política. Aquélla encuentra su expresión en las diversas manifestaciones de la Cultura», «Editorial», Revista Nacional de Educación, 22 (1942): 4.

${ }^{24}$ «Editorial», Revista Nacional de Educación, 23 (1942): 3-5.

25 «iDesdichadas aquellas naciones que no cultivan, como una parcela predilecta de su jardín interior, esta inmaterial política del espíritu! Porque sólo a través de ella y de las diversas 
doctrina que sirviera a la acción ${ }^{26}$, que pudiera concretarse en política y consolidara el Estado surgido de la guerra.

En un segundo plano, la revista publicó artículos escritos por esos grandes nombres ya mencionados, a los que Ibáñez Martín a veces concedía un rol concreto o, simplemente, buscaba reunir en torno al Estado. Entre ellos hubo escritores notables como Manuel Machado o Gerardo Diego ${ }^{27}$. De hecho, desde el primer número aparecieron textos literarios o de tema estrictamente cultural y en el tercero nacieron las secciones de Letras y Arte, que tuvieron una vida intermitente y nombres diversos. Estas colaboraciones, mezcladas con textos de intención política y otros de carácter docente, dieron un tono misceláneo a la Revista Nacional de Educación y, a su vez, en la mayoría de las ocasiones hacen imposible delimitar cuánto de ideología, interés político, divulgación cultural, pedagogía o arte hay en cada texto, pues fue esta peculiar mezcla, promovida por Ibáñez Martín, la que caracterizó no solo a la revista, sino también al Ministerio de Educación Nacional.

\section{Ministerio, CREACIÓN Y REFORMA (1941-1945)}

El discurso que cada año pronunciaba el ministro en la apertura del curso universitario, publicado en el número correspondiente de la Revista Nacional de Educación, era lo más parecido a un balance entusiasta del año educativo, en el que Ibáñez Martín repasaba éxitos y planes. Los proyectos ministeriales fueron hasta 1945 un contenido usual en la revista. El más destacado en esta época de promesas fue el referido a la universidad, institución que para el ministro debía ser, como afirmó en la apertura del curso 1940-1941, «el vértice auténtico de la más profunda, definitiva y revolucionaria transformación social $»^{28}$.

Los editoriales de la Revista Nacional de Educación fueron dando a conocer las líneas maestras de esta reforma. También alguna variación importante. La investigación, uno de los quehaceres clásicos de la universidad, fue uno de los problemas clave. En 1939, la primera obra significativa de Ibáñez Martín había sido la creación del Consejo Superior de Investigaciones Científicas (CSIC). En julio de 1941, la Revista Nacional de Educación publicó su primer editorial dedicado a la universidad, en el que describía al CSIC como el instrumento para la

manifestaciones de la Cultura, se fija la trayectoria permanente del Estado con un profundo sentido de universalidad», «Editorial», Revista Nacional de Educación, 23 (1942): 4.

${ }^{26}$ Véase «Editorial», Revista Nacional de Educación, 24 (1942): 4.

${ }_{27}$ Cartas de Ibáñez Martín, José a Machado, Manuel y Diego, Gerardo, 22/11/1940, AGUN, 139, 10 y 21.

28 «El Caudillo inaugura el curso académico en Valladolid», Revista Nacional de Educación, 1 (1941): 98. 
revolución en el ámbito de la ciencia, entendida ésta de acuerdo con la definición unamuniana de «algo vivo en vías de formación siempre, con su fondo formado y eterno y su proceso de creación $\rangle^{29}$. Ahora, de acuerdo con la revista, terminado el curso académico y realizada la depuración de la universidad, la acción ministerial se detenía en la institución misma. El editorial apuntaba a una reforma en clave falangista donde la universidad, además de científica, sacrificara su autonomía para, unificada de alguna manera, sirviera al Estado y educara a los españoles. Sin negar la función científica pura de la universidad, el editorial le restaba importancia por la misión nacionalizadora.

En el número de octubre de 1941, con motivo de la apertura de curso universitario, el editorial glosó el discurso de Ibáñez Martín, en el que adelantó los ejes de la reforma. El carácter unificador demandado parecía satisfecho por el proyecto de reforma, que «en su configuración totalitaria, integra y armoniza toda la cultura, todos los órganos docentes, todos los elementos de creación y difusión de la ciencia, que se abrazan en una unidad pedagógica para servir los ideales católicos y políticos de la gran España que renace» ${ }^{30}$. Sin embargo, resulta significativo e indica un cambio de orientación en los editoriales «universitarios», que la revista mencionara que los Colegios Mayores podían regirlos también instituciones privadas ${ }^{31}$.

El editorial dedicaba a la función investigadora una mención imprecisa. La universidad debía «crear ciencia desarrollando el espíritu de investigación»» Se entiende el recelo que podía suscitar esta expresión vaga si se tiene en cuenta que era común afirmar el carácter de «laboratorio» de la universidad y el CSIC había sido criticado por sustraerle parte de esta investigación ${ }^{33}$. ¿Qué destino le deparaba la reforma? Como hemos visto, ya la aspiración de unificar el control de la enseñanza perdía fuerza en el aspecto educador con la posible titularidad privada de los Colegios Mayores.

Los proyectos de entonces no eran pequeños. José María Albareda, edafólogo y colaborador de Ibáñez Martín, había impulsado la idea de fundar el CSIC. Con ocasión de su nombramiento como académico de Ciencias, una semblanza publicada en la revista se felicitaba de que fuera capaz del «difícil menester de despertar una era de renacimiento científico ${ }^{34}$. La Revista Nacional de Educación informó también de cada uno de los plenos anuales del CSIC, presididos por Franco, que se convirtieron, por la relevancia del organismo y

29 «Editorial», Revista Nacional de Educación, 7 (1941): 3.

30 «Editorial», Revista Nacional de Educación, 10 (1941): 3.

31 Véase «Editorial», Revista Nacional de Educación, 10 (1941): 5.

32 «Editorial», Revista Nacional de Educación, 10 (1941): 4.

33 Véase PÉREZ LÓPEZ, 2016: 217.

${ }^{34}$ Ortiz Muñoz, Luis, «Semblanza de José María Albareda», Revista Nacional de Educación, 18 (1942): 91. 
sus trabajos, así como por su potencial propagandístico, en una de las citas más importantes de la cultura española. Cada pleno era inaugurado por el ministro, que pronunciaba un discurso, también publicado por la revista, en el que desarrollaba los principios del CSIC, el trabajo de los Patronatos, Institutos y Secciones, sus revistas e instalaciones ${ }^{35}$.

El CSIC fue una iniciativa típica del Estado español de la posguerra, que se consideraba legitimado para imprimir su dirección a la ciencia. También hizo lo posible por bautizarla: una crónica de la Revista Nacional de Educación explicó que la futura iglesia del Espíritu Santo, destinada a ser la capilla del Consejo, era la primera iglesia que construía un Ministerio de Educación Nacional ${ }^{36}$. A través de sus crónicas, la Revista Nacional de Educación se ocupó también de Patronatos e Institutos concretos, como el Juan de la Cierva, significativo en cuanto su misión era el desarrollo técnico de la industria española ${ }^{37}$. O el Instituto San José de Calasanz de Pedagogía, importante para la reforma educativa emprendida por el propio Ministerio de Educación Nacional ${ }^{38}$. Además, la revista publicó algunos reportajes que describían la labor del Consejo ${ }^{39}$, órgano cuya misión, en el fondo, se discutía en los estadios previos a la aprobación de la Ley de Ordenación Universitaria.

Si los editoriales permiten seguir las ideas detrás de la reforma universitaria y algunos de sus avatares, hay que detenerse también en los artículos de los colaboradores. Buena parte de los contenidos sobre materia universitaria giraron en torno a la nueva ley. Cuando en algún número apareció alguna sección específica, llamada «Universidad» o «Temas universitarios», albergó ideas para la reforma. En el ámbito concreto de las facultades y estudios, encontramos artículos de Fernando Enríquez de Salamanca y Carlos Jiménez Díaz para la Medicina, Dámaso Alonso y Antonio Tovar en Filología, Manuel Lora Tamayo y Arnold Eucken en Ciencias, Santos Ruíz y José María Albareda en Farmacia y Victoriano Colomo en Veterinaria ${ }^{40}$.

35 Por ejemplo: «Hacia una nueva ciencia española», Revista Nacional de Educación, 1 (1941): 93-98.

36 «La Iglesia del Espíritu Santo», Revista Nacional de Educación, 28 (1943): 94.

37 Véase «La ciencia española al servicio de la Economía», Revista Nacional de Educación, 3 (1941).

38 Véase «El Instituto de Pedagogía», Revista Nacional de Educación, 5 (1941): 97-99.

39 Véase, por ejemplo, «Recapitulación sobre la tarea investigadora de España», Revista Nacional de Educación, 25 (1943); «Actividades del Consejo Superior de Investigaciones Científicas», Revista Nacional de Educación, 43-44 (1944) y «Tres reuniones científicas en Navarra», Revista Nacional de Educación, 45 (1944).

${ }^{40}$ Véase Enríquez de Salamanca, Fernando, «Los Estudios Médicos en España», Revista Nacional de Educación, 1 (1941): 29-32. Jiménez Díaz, Carlos, «Bases esenciales para la mejor enseñanza de la Medicina», Revista Nacional de Educación, 4 (1941): 47-56. Alonso, Dámaso, «Sobre la enseñanza de la Filología Española», Revista Nacional de Educación, 2 (1941): 21-39. Tovar, Antonio, «Preocupaciones sobre la enseñanza universitaria de la Filología Clásica», 
Otras colaboraciones se remontaron a la historia de la Universidad española, cuyas glorias eran lugar común entre los reformistas. José Navarro Latorre, por ejemplo, justificaba en un artículo sobre la Universidad medieval que sus «íntimas virtudes han de servir de base para todo esfuerzo que se proyecta sobre el futuro cultural de nuestra Patria» ${ }^{41}$. Además, la revista proporcionó también inspiración del extranjero, como muestran artículos sobre Alemania, Estados Unidos, Japón, la India y el mundo musulmán ${ }^{42}$.

Algunos rectores participaron con opiniones de fondo, como Carlos Ruiz del Castillo, rector de la Universidad de Santiago de Compostela, que se manifestó a favor de que el Estado interviniera en la Universidad ${ }^{43}$. La crisis de la universidad procedería de su desvinculación, durante el siglo XVIII, de los problemas reales a los que antaño había atendido, por ejemplo, la Universidad de Bolonia en materia de Derecho. También de haber abdicado de su misión de sintetizar el saber, unificarlo y pulir lo accesorio para llegar al núcleo de los problemas. Para Ruiz del Castillo, la dimensión institucional y corporativa de la universidad la convertía en parte de una sociedad, motivo por el cual no podía permanecer ajena a los problemas de su tiempo. Sin embargo, la fórmula que proponía el rector de Santiago era claramente estatista.

«Estado de Cultura» se llamó hace ya tiempo en Alemania al Estado que interviene en la vida social y no se limita a presidirla. El Estado total, síntesis de Derecho y de Cultura, integración de la vida social, a la cual conduce en la dirección

Revista Nacional de Educación, 11 (1941): 7-15. Lora Tamayo, Manuel, «Orientaciones para una posible reforma de la Facultad de Ciencias», Revista Nacional de Educación, 2 (1941): 41-50. Eucken, A., «Problemas de la enseñanza superior en el campo de la química técnica», Revista Nacional de Educación, 22 (1942): 115-118. En el número 3, aparece la sección «Universidad». Santos Ruiz, Ángel, «La reforma de la Facultad de Farmacia», Revista Nacional de Educación, 3 (1941): 15-29. Albareda, José María, «Universidad, Farmacia y Vida rural», Revista Nacional de Educación, 30 (1943): 46-68. Albareda dio también su opinión sobre la Facultad de Ciencias. Colomo, Victoriano, «Las escuelas de Veterinaria», Revista Nacional de Educación, 4 (1941): $65-70$.

${ }^{41}$ Navarro Latorre, José, «La universidad en el siglo XIII», Revista Nacional de Educación, 31 (1943): 47.

${ }_{42}$ Véase, por ejemplo, «La Universidad alemana», Revista Nacional de Educación, 3 (1941) y «Las Universidades de Estados Unidos, del Japón y de la India», Revista Nacional de Educación, 17 (1942). El resto de información en el número 19, y, hasta poco después de la reforma, los números Revista Nacional de Educación, 21 (Paraguay), 28 (Suiza), 29 (Bulgaria) y 36 (Rumanía).

${ }^{43}$ A Ruiz del Castillo, rector de Santiago de Compostela, Ibáñez Martín le había pedido un artículo sobre «la concepción moderna de la Universidad española», carta de Ibáñez Martín, José a Ruiz del Castillo, Carlos, 18/09/1940, AGUN, 139, 34. 
unitaria que señala el destino de un pueblo en marcha, ha de dar a la Cultura un rango decisivo en la ordenación de los valores y de las fuerzas nacionales ${ }^{44}$.

La intervención en la universidad de este Estado integrador ponía a la antigua corporación al servicio de los intereses estatales. ¿Quién concretaba estos intereses? Con toda probabilidad, el ministro de Educación Nacional y su equipo, entre los cuales, por cierto, cabría incluir a los rectores. Ruiz del Castillo terminaba su colaboración en la revista con un fragmento del discurso de Ibáñez Martín en la apertura del curso 1939-1940, prueba de la sintonía entre ambos y del estatismo común, pues el ministro se refería a la misión del Estado de «velar por la unidad de la Ciencia» ${ }^{45}$.

También opinaron sobre aspectos concretos de la reforma el rector de la Universidad de Oviedo, Sabino Álvarez-Gendín, y José Escobedo, rector de la Universidad de La Laguna ${ }^{46}$. Sobre el rumbo del proyecto escribió bajo pseudónimo «Italicus» ${ }^{47}$. Gregorio González-Roldán considera que puede tratarse de Luis Ortiz Muñoz, natural de Sevilla, colaborador de Ibáñez Martín, nombrado Director General de Enseñanza Media en 1942 y uno de los redactores del anteproyecto de reforma de la universidad ${ }^{48}$. En diciembre de 1941, mientras se debatía en el Consejo Nacional de Educación, del que era secretario general, precisó que, si bien la investigación, la docencia y la instrucción de profesionales eran tres funciones universitarias, la nueva ley pondría el acento en recuperar la docencia universitaria ${ }^{49}$.

Este era un aspecto descuidado, pues muchos catedráticos cargaban la docencia en los profesores auxiliares y se enfrascaban en sus investigaciones. No obstante, Italicus también consideraba que la investigación debía exigirse a todo profesor universitario. «El Catedrático que no siente la curiosidad científica, ni el amor a la investigación, ni el afán de renovar y pulir su bagaje cultural, no merece, por estancado y rutinario, el nombre digno de intelectual y de maestro» ${ }^{50}$, escribía. Pero, ¿qué formula proponía para coordinar la docencia y

${ }_{44}$ Ruiz del Castillo, Carlos, «Crisis y horizonte de la universidad», Revista Nacional de Educación, 1 (1941): 28.

${ }^{45}$ Ruiz del Castillo, Carlos, «Crisis y horizonte de la universidad», Revista Nacional de Educación, 1 (1941): 28.

46 Véase Álvarez-Gendín, Sabino, «La Reforma Universitaria», Revista Nacional de Educación, 8 (1941): 7-11. Escobedo, José, «El profesorado universitario», Revista Nacional de Educación, 20 (1942): 25-27.

${ }^{47}$ Italicus [Ortiz Muñoz, Luis], «Ante la reforma universitaria: la docencia, la investigación y la profesionalidad», Revista Nacional de Educación, 12 (1941): 27-33.

48 Véase GONZÁLEZ ROLDÁN, 1985, vol. 1: 303.

49 Véase Italicus [Ortiz Muñoz, Luis], «Ante la reforma universitaria: la docencia, la investigación y la profesionalidad», Revista Nacional de Educación, 12 (1941): 30.

${ }^{50}$ Italicus [Ortiz Muñoz, Luis], «Ante la reforma universitaria: la docencia, la investigación y la profesionalidad», Revista Nacional de Educación, 12 (1941): 30. 
la investigación? La investigación quedaría encauzada en la nueva ley a través del Consejo Superior de Investigaciones Científicas, que tendría la competencia de establecer pequeñas secciones en las universidades para acoger y dirigir la investigación realizada. Esto suponía, claro, un límite en torno al proyecto totalizador de la Universidad. Y a la par, por cierto, podía disgustar a muchos universitarios que consideraban que la investigación era un atributo exclusivamente universitario o, cuando menos, una de sus funciones esenciales. ¿Se conformarían los profesores universitarios con no ser «corporación de investigadores, sino centro de formación de los mismos $»^{51}$ como proyectaba el Ministerio de Educación Nacional?

En agosto de 1942, el editorial de la Revista Nacional de Educación confirmaba que la investigación quedaba en manos de una institución extrauniversitaria, el CSIC. Nótese que, a pesar de las pretensiones vigentes de que la universidad fuera totalizadora integrando centros nacidos fuera de ella, como los profesionales ${ }^{52}$, no abarcaba una de sus misiones tradicionales. En esta realidad no repara el editorial, que señala que la universidad es investigadora en otro sentido, en cuanto enseña a amar la investigación a los estudiantes o anima a sus profesores a investigar.

... en realidad no es auténtica misión universitaria la creación de la investigación, sino más bien la formación de los investigadores. Importa subrayar aún más este concepto. No queremos en este punto una Universidad al estilo germánico, cargada de seminarios y convertida en una red de Institutos de investigación ${ }^{53}$.

Casi un año después, el editorial del número de julio de 1943 demostraba que el proyecto de la ley había evolucionado con algunos cambios significativos. En el área de sus funciones, la universidad asumía al menos parte de la función investigadora, coordinándose con el CSIC «dotando a todas las Cátedras de los medios suficientes para la creación de ciencia, y haciendo posible que surjan en el seno de la Universidad centros y núcleos de una rama determinada de la investigación científica $\rangle^{54}$. Además, el editorial omitía la función de la universidad como institución que, al servicio del Estado, rigiera todo el ámbito de la educación.

${ }^{51}$ Italicus [Ortiz Muñoz, Luis], «Ante la reforma universitaria: la docencia, la investigación y la profesionalidad», Revista Nacional de Educación, 12 (1941): 32.

${ }_{52}$ Italicus [Ortiz Muñoz, Luis], «Ante la reforma universitaria: la docencia, la investigación y la profesionalidad», Revista Nacional de Educación, 12 (1941): 27-33.

53 «Editorial», Revista Nacional de Educación, 20 (1942): 4.

54 «Editorial», Revista Nacional de Educación, 31 (1943): 4. 
La Ley de Ordenación de la Universidad española fue publicada en el número de agosto-septiembre de $1943^{55}$ en la sección dedicada a la legislación ministerial. El artículo 26 explicaba que las cátedras debían estar dotadas para la investigación. Cuando ésta excediera sus posibilidades se crearían Institutos de Investigación Científica como secciones de los Institutos Nacionales del CSIC. El mismo año en que se aprobó y en fecha tan señalada como el 12 de octubre de 1943, fue inaugurada la Ciudad Universitaria. El editorial del número de octubre, monográfico, se recreaba en el simbolismo de las nuevas construcciones, edificadas donde durante la guerra había estado el frente de Madrid $^{56}$. Pero la reforma había comenzado el año anterior con los Colegios Mayores. Y se extendió hasta 1944 con los decretos sobre las Facultades. Estos fueron glosados por Antonio Ortiz Muñoz, activo colaborador de la revista, en un artículo en donde informaba y comentaba los aspectos más señalados de los siete decretos, uno por cada Facultad: Filosofía y Letras, Derecho, Ciencias, Medicina, Farmacia, Veterinaria y Ciencias Políticas y Económicas ${ }^{57}$.

En el controvertido asunto del lugar de la investigación científica en la universidad, debió de ser relevante la opinión de José María Albareda, secretario general del CSIC, que en sendos discursos publicados en la Revista Nacional de Educación defendió la dimensión formativa de la investigación en el ámbito de la educación superior. El primero fue su discurso de ingreso como académico de Ciencias Exactas, Físicas y Naturales el 3 de junio de 1942. El secretario general del CSIC señaló entre las funciones universitarias la investigadora, que debía desarrollarse con equilibrio, sin «enturbiar la serena claridad de la enseñanza ${ }^{58}$. Unos días antes, el 28 de mayo de 1942, Albareda también había ingresado como académico de número en la Real Academia de Farmacia. En su discurso reflexionó también sobre la docencia y la investigación universitaria, asunto que debía llevar al profesor a pensar más allá de su asignatura y apreciar a sus alumnos. A través de la investigación, el profesor debía introducir a los estudiantes en la ciencia y ofrecerles un mundo más ancho al que estaban acostumbrados. Además, Albareda pensaba que la investigación era un servicio a Dios y a la patria. En este sentido, el trabajo desempeñado en las cátedras podía resolver los problemas nacionales ${ }^{59}$. El secretario general del CSIC no compartimentaba las funciones de la cultura ni independizaba la labor

55 Véase «Documentación Legislativa», Revista Nacional de Educación, 32-33 (1943): 109-166.

56 «Editorial», Revista Nacional de Educación, 34 (1943): 3-5.

57 Véase Ortiz Muñoz, Antonio, «La ordenación jurídica de nuestros estudios universitarios», Revista Nacional de Educación, 46 (1944): 62-73.

58 Albareda, José María, «Valor formativo de la investigación», Revista Nacional de Educación, 18 (1942): 22.

59 Véase Albareda, José María, «Universidad, Farmacia y Vida rural», Revista Nacional de Educación, 30 (1943): 43-68. 
investigadora como si solo la universidad fuera investigadora o la investigación debiera realizarse exclusivamente en el seno del Consejo.

Sin ser un boletín de noticias, la revista ofrece un panorama del sistema educativo y científico español de la posguerra, aunque nosotros nos hemos detenido en el aspecto investigador. La nueva legislación educativa del régimen fue un contenido vertebral de la revista hasta 1945, cuando se aprobó la última de las grandes leyes de educación del período Ibáñez Martín: la Ley de Educación Primaria. Como ha escrito Miguel Jerez, la revista «tiene el valor indudable, a efectos de investigación, de ser reflejo de la política educativa del Régimen ${ }^{60}$. Entre 1941 y 1945, la revista divulgó las ideas que inspiraron los proyectos legislativos de Ibáñez Martín y publicó trabajos que sirvieron de fundamento a sus políticas. Este material es un testimonio de los problemas que debió afrontar, de las influencias más notables y de las soluciones que adoptaron él y sus colaboradores.

\section{Revista nacional: los límites de la Falange}

La «política del espíritu» llevó a la Revista Nacional de Educación a participar en el esfuerzo intelectual de dotar de doctrina al régimen surgido de la Guerra Civil española. Se dio la circunstancia de que en este trabajo la revista no estaba sola en el ámbito ministerial, pues también participaban organismos como la universidad (de cuyas actividades informó con puntualidad) y sus catedráti$\cos ^{61}$. Un modelo lo constituye el artículo «Ideas para una Filosofía de la Historia de España» que era, en realidad, el discurso de apertura del curso $1942-1943^{62}$ en la Universidad Central, pronunciado por Manuel García Morente.

García Morente, catedrático de Ética, es también un buen ejemplo del rumbo que toma España el 18 de julio de $1936^{63}$. Discípulo de Ortega y decano de la Facultad de Filosofía y Letras entre 1931 y 1936, fue destituido pocos días después de la sublevación militar y hubo de refugiarse en París, donde se convirtió al catolicismo. Para reunir algo de dinero, cruzó el Atlántico y pronunció una conferencia en Montevideo («Orígenes del nacionalismo español») y dos en Buenos Aires («España como estilo», «El caballero cristiano»). Gonzalo Redondo ha hablado de una doble conversión de García Morente. La

${ }^{60}$ JEREZ, 1978: 181.

${ }^{61}$ Miguel Jerez ha reparado en que «aproximadamente uno de cada cuatro de las personas que integran el cuadro de colaboradores eran catedráticos de Universidad, y otros, por lo menos, iban a serlo relativamente pronto», JEREZ, 1978: 186.

${ }^{62}$ Véase García Morente, Manuel, «Ideas para una Filosofía de la Historia de España», Revista Nacional de Educación, 22 (1942): 29-100.

${ }^{63}$ Véase REDONDO GÁLVEZ, 1999, vol. 1: 39-55. 
conversión religiosa le lleva a ser ordenado sacerdote en Madrid en 1940, su conversión «cultural» es patente en sus conferencias en Uruguay y Argentina, y también en el artículo publicado en la Revista Nacional de Educación. En estas «Ideas» identifica la filosofía de la Historia de España con la hispanidad, y el servicio a la patria con la vivencia del catolicismo.

Manuel García Morente se convirtió, desde el punto de vista cultural, al tradicionalismo, como si tal conversión fuera añadidura obligada para todo el que recuperara la $\mathrm{fe}^{64}$.

La revista fue nacional en cuanto a su difusión. Sin embargo, más que un medio de comunicación integrador, fue un instrumento de partido. Es la revista del Ministerio de Educación Nacional del bando ganador en la guerra, al que se han encomendado misiones propias de «política del espíritu». El color beligerante y falangista que prometía el primer número de la revista se mantuvo durante una primera etapa que llega hasta mediados de 1942.

También mantuvo, hasta el número fechado en agosto de 1942, detalles propios de la propaganda de guerra, en forma de imágenes y, sobre todo, textos breves de lenguaje contundente. Por ejemplo, un retrato del general Franco adorna el primer número con el siguiente pie de foto: «Impulsor supremo de la cultura nacional, artífice y genio de nuestras victorias en la batalla de las armas $\mathrm{y}$ de las letras $\rangle^{65}$. También incluía un fragmento del discurso pronunciado por Franco al Sindicato Español Universitario (SEU) el 12 de octubre de 1937 y otros de José Antonio deseando un paraíso custodiado por ángeles con espadas o soñando la vanguardia para la Falange.

El primer editorial llamaba a la revolución española, «de esta España que proclama su fe en la Falange como instrumento de su renovación cultural» ${ }^{66}$. Daba a entender que ésta debía hacerse, por un lado, frente a la generación que había roto con la tradición, a la que contraponía «una cultura inmutable» ${ }^{67}$ verdaderamente española que había sobrevivido y derramado su sangre en la guerra pasada.

Con efecto de dar a conocer las corrientes políticas que nutrieron la revista y participaron en el esfuerzo de construcción intelectual del «nuevo Estado», vale la pena detenerse en una diferencia de criterio entre el «estatismo» de Falange y la postura de la Iglesia. En el ámbito de la educación, no había propiamente una doctrina falangista. Ni siquiera aquellas ideas «joseantonianas» propagadas en forma de citas directas constituían un corpus monolítico. Como

${ }^{64}$ Véase REDONDO GÁLVEZ, 1999, vol. 1: 49.

${ }^{65}$ Revista Nacional de Educación, 1 (1941): 2.

${ }^{66}$ «Editorial», Revista Nacional de Educación, 1 (1941): 5.

67 «Editorial», Revista Nacional de Educación, 1 (1941): 3. 
respuesta a esta circunstancia hay que situar la aparición en abril de 1941 de la sección «Voz de la Falange».

En una crónica titulada «Escuela azul», la revista había prometido que se llevarían a la práctica «las ideas de los pensadores que aquí viertan sus preocupaciones filosófico-pedagógicas» ${ }^{68}$. Cuando nació la sección «Voz de la Falange», parecía constituida para potenciar un núcleo de pensamiento falangista en materia educativa. Por el momento, el primer artículo fue escrito por Pedro Laín Entralgo: «Educación del ímpetu». Dedicado «a los maestros del Sindicato Español del Magisterio» ${ }^{69}$, ya lo había publicado durante la guerra en la Revista de Educación Hispánica. Para el número inaugural de la revista, Laín Entralgo había recibido la solicitud de un artículo «sobre el Partido y la Universidad ${ }^{70}$, un tema que, como el establecimiento de Facultades de Teología en las universidades del Estado encargado a Plá y Deniel, era uno de los asuntos conflictivos de la reforma universitaria.

El siguiente artículo de la sección lo escribió José Ibáñez Martín. Esto puede resultar paradójico, pues antes de ser nombrado ministro no había pasado de mantener relaciones cordiales con los falangistas y durante la Guerra Civil apenas había militado formalmente en FET y de las JONS. Pero parece que esta aventura doctrinal falangista suscitó su interés y contribuyó con la publicación del discurso que había pronunciado en la inauguración del Instituto de Cultura Alemana ${ }^{71}$.

Ya en el primer número de la revista habían colaborado los aliados militares del bando nacional. Por ejemplo, participaban Giuseppe Bottai, ministro de Educación italiano, sobre la Carta de la Escuela, y Guillermo Petersen, agregado cultural de la embajada alemana, con un artículo titulado «Nueva Pedagogía en Alemania» ${ }^{72}$. Petersen representaba al ministro de Educación del Reich, Bernhard Rust, al que se le había solicitado un artículo «sobre nuevas orientaciones de la política docente germánica ${ }^{73}$. Ibáñez Martín había escrito a Bottai pidiéndole estas orientaciones en el caso de la Italia fascista ${ }^{74}$. Un mes

\footnotetext{
68 «Escuela Azul», Revista Nacional de Educación, 3 (1941): 112.

${ }^{69}$ Véase Laín Entralgo, Pedro, «Educación del ímpetu», Revista Nacional de Educación, 4 (1941): 7-26.

70 Carta de Ibáñez Martín, José a Laín Entralgo, Pedro, 18/09/1940, AGUN, 139, 19.

71 Véase Ibáñez Martín, José, «La confluencia de las culturas germana e hispana», Revista Nacional de Educación, 6 (1941): 7-13.

${ }^{72}$ La Revista Nacional de Educación también incluía una página propagandística sobre «La Universidad alemana durante la guerra». Las recensiones eran de publicaciones alemanas, aunque en números siguientes la revista dedica también espacio a la cultura de Inglaterra y Francia. La sección de libros se mantuvo en los diez años de la revista.

${ }^{73}$ Carta de Ibáñez Martín, José a «Rust Hen Rubht» [Rust, Bernhard], 18/09/1940, AGUN, 139, 17.

${ }^{74}$ Véase carta de Ibáñez Martín, José a Bottai, Giuseppe, 18/09/1940, AGUN, 139, 6.
} 
más tarde, el ministro español le agradeció la recepción del texto «Lavoro e lavoratori nella Carta della Scuola» y manifestaba su deseo de verle cuando visitara España ${ }^{75}$. Bottai veía en la revista una oportunidad de reforzar los vínculos culturales entre su país y España ${ }^{76}$.

El siguiente artículo (y último) publicado en «La Voz de la Falange» eran unos «Apuntes sobre la filología clásica desde España» de Antonio Tovar" Este era otro de los personajes destacados de la Falange política y cultural. Pero su aportación a este esfuerzo de política educativa fue más académico que ideológico, aunque no exento de espíritu revolucionario, pues lanzaba una propuesta de renovación de los estudios de Filología. En realidad, el único intento de entidad de exponer en la revista una aplicación político-educativa de la doctrina falangista fue el artículo «Ensayo sobre una Pedagogía Nacionalsindicalista» de Gerardo Gavilanes, consejero nacional del SEU, en febrero de $1942^{78}$.

El artículo de Gavilanes, muy breve, iba a constituir el primero de una serie de ensayos. Pero suscitó tal polémica que el autor solo publicó, dos meses más tarde, una nota de rectificación. En su primer artículo, en efecto, Gavilanes defendía un control totalitario de la educación por parte del Estado que iba demasiado lejos de lo posible entonces y de lo que, por ejemplo, estaba dispuesta a tolerar la Iglesia. Gavilanes era consciente de que el tema era polémico, porque desde un principio matizó su propuesta aludiendo a una libertad crítica de la sociedad, al papel de la familia o a la libertad religiosa ${ }^{79}$. Pero era evidente que iba en otra línea, pues la libertad crítica servía tan solo para reconocer autoridades a las que luego debía obedecerse indiscutiblemente. Afirmaba que la familia «vive única y exclusivamente de la comunidad de todas las células, es decir, del propio Estado» ${ }^{80}$. Y la libertad religiosa no quedaba del todo precisaba: parecía ser una mera facultad de organización de la Iglesia. Gavilanes exigía claramente «toda la hegemonía educativa para el Estado» ${ }^{81}$ con una pequeña libertad para la cultura tampoco aclarada.

75 Véase carta de Ibáñez Martín, José a Bottai, Giuseppe, 23/10/1940, AGUN, 139, 6.

${ }^{76}$ Véase carta de Bottai, Giuseppe a Ibáñez Martín, José, 6/11/1940, AGUN, 139, 6.

77 Véase Tovar, Antonio, «Apuntes sobre la Filología Clásica desde España», Revista Nacional de Educación, 7 (1941): 7-16.

78 Véase Gavilanes, Gerardo, «Ensayo sobre una Pedagogía Nacionalsindicalista», Revista Nacional de Educación, 14 (1942): 27-29. Gerardo Gavilanes Verea fue también Secretario Central del Servicio Español del Magisterio (S.E.M.).

79 «Pudiera ser que algunos no quieran comprender mis palabras o intenten interpretarlas en sentido doble. Me es indiferente. Con Behn afirmo. Quien cree, comprenderá», Gavilanes, Gerardo, «Ensayo sobre una Pedagogía Nacionalsindicalista», Revista Nacional de Educación, 14 (1942): 29.

${ }^{80}$ Gavilanes, Gerardo, «Ensayo sobre una Pedagogía Nacionalsindicalista», Revista Nacional de Educación, 14 (1942): 27.

${ }^{81}$ Gavilanes, Gerardo, «Ensayo sobre una Pedagogía Nacionalsindicalista», Revista Nacional de Educación, 14 (1942): 28. 
El hecho de exigir toda hegemonía educativa para el Estado, permite con el tiempo anular esa masa amorfa que - en el mejor de los casos-, bien sugestionable, es dirigida a un fin determinado por elementos extraños a la política estatal. (...). Si dejáramos a otras estirpes la educación primal y política de la juventud, es muy posible pudieran perderse valores de tipo nacional ${ }^{82}$.

La propuesta que hacía Gavilanes era que la primera enseñanza fuera estatal y obligatoria. Así, la Falange se aseguraría formar a las generaciones en su doctrina y evitar la indiferencia con la que los jóvenes, solo interesados en lo profesional, llegaban a la Falange. Por ello sugería este control estatal de la enseñanza primaria. El malestar que suscitó este artículo en algunos católicos ya ha sido estudiado ${ }^{83}$. En abril la Revista Nacional de Educación publicó una página de Gavilanes en la que, además de rectificar, daba un sentido por completo contrario a sus palabras anteriores. Por un lado, esgrimía su condición de católico. Con respecto a la familia, daba la vuelta a las ideas de su artículo sobre su dependencia del Estado. En el primer artículo decía que «su destino y orientación en la vida es la de servirle».

Otra errata que oscurece el concepto vertido en mi artículo, en el tercer párrafo de su primera página, me hace decir que «la familia no vive sino del Estado, ni tiene más razón de ser que servirle»; cuando en realidad debiera decir: «... que la familia es el todo sin el Estado. La familia, célula primaria de aquél, vive por sí, pero única y exclusivamente se perfecciona por medio de la comunidad de todas las células, es decir, del propio Estado. Y ello es así, por cuanto su destino y orientación en la vida es la de servirla» ${ }^{84}$.

Gerardo Gavilanes reiteró que se trataba de un mero ensayo, de un «bosquejo» ${ }^{85}$, pero la realidad es que no continuó con la serie prometida. Tampoco volvió a plantearse en la revista un proyecto de Falange para la enseñanza. Aunque su primer artículo hubiera sido, en efecto, un cúmulo de erratas mal interpretado, solo el hecho de que tuviera que rectificar muestra que ni existía un pensamiento único en materia educativa ni los proyectos totalitarios eran hegemónicos. También denota el interés de la Iglesia en que no se cuestionara el principio de la libertad de enseñanza, ejercido a través de sus centros educativos.

La Revista Nacional de Educación también recogió lo que podemos considerar como opinión católica en materia de educación. Su exponente fue el padre dominico Silvestre Sancho, rector de la Universidad de Manila, que publicó en la revista un artículo sobre la Divini Illius Magistri (1929), la

${ }^{82}$ Gavilanes, Gerardo, «Ensayo sobre una Pedagogía Nacionalsindicalista», Revista Nacional de Educación, 14 (1942): 28.

83 Véase ALFONSO SÁNCHEZ, 1999: 97-100.

${ }^{84}$ Gavilanes, Gerardo, «Aclaración», Revista Nacional de Educación, 16 (1942): 34.

${ }^{85}$ Gavilanes, Gerardo, «Aclaración», Revista Nacional de Educación, 16 (1942): 34. 
encíclica en la que Pío XI criticaba algunos problemas que detectaba en su tiempo, como la pretensión de algunos Estados de arrogarse el derecho exclusivo de educar a la juventud. En ella también había señalado la libertad de enseñanza como un derecho de la sociedad y de la Iglesia. En su artículo, el padre Silvestre Sancho alertaba de que aún había personas que sostenían la doctrina liberal en materia educativa. Aunque no hacía ninguna precisión al respecto, era sabido que una de las consecuencias políticas del orden liberal había sido la intervención arbitraria del Estado en la educación y dedicó una parte de su comentario a la encíclica a delimitar su función, ordenada al bien común, que era amparar la labor educativa de los padres, respetar los derechos de la Iglesia y «educar a sus ciudadanos según las directrices y características fundamentales de raza, historia y vida ${ }^{86}$ correspondientes.

En otro momento, Sancho criticaba que pervivía «mucho institucionismo-odres viejos-que pretende disfrazarse de católico-vino nuevo» ${ }^{87}$. Con esta alusión a la Institución Libre de Enseñanza pretendía aludir, sin duda, a la doctrina pedagógica emanada del krausismo, que poseía un enfoque antropológico espiritual, pero no católico. Para el dominico no bastaba tampoco desarrollar las potencias del niño si su vida no se enfocaba al bien más alto de su salvación para la vida eterna. Este era el fin de la educación católica «y [el] educador que pierda de vista ese fin, deja de ser educador cristiano, aunque a voz en cuello pregone su cristianismo con base más o menos patriótica, que siendo una base muy buena y digna de atención, no es, ni mucho menos, la base única de nuestras posiciones doctrinales» ${ }^{88}$. Este bien pudiera ser un mensaje al sector falangista, además de una definición del objetivo de la educación cristiana.

Al final de su artículo, el dominico recogía el canon que permitía a la Iglesia fundar un establecimiento de enseñanza superior al igual que escuelas y centros de enseñanza media. No obstante, el rector de la Universidad de Manila también criticó a quienes esgrimían sus propios derechos como si fueran los de la Iglesia. Quizá se refería a otra polémica, en torno a la «educación patriótica» ${ }^{89}$, materia con la que Sancho estaba de acuerdo y a la que algunos colegios de religiosos ponían objeciones. El padre dominico recordaba que «las instituciones

${ }^{86}$ Sancho, Silvestre (O. P.), «La educación cristiana a la luz de la 'Divini illius magistri'», Revista Nacional de Educación, 28 (1942): 39.

${ }^{87}$ Sancho, Silvestre (O. P.), «La educación cristiana a la luz de la 'Divini illius magistri'», Revista Nacional de Educación, 28 (1942): 31.

${ }^{88}$ Sancho, Silvestre (O. P.), «La educación cristiana a la luz de la 'Divini illius magistri'», Revista Nacional de Educación, 28 (1942): 34.

${ }^{89}$ Véase Sancho, Silvestre (O. P.), «La educación cristiana a la luz de la 'Divini illius magistri'», Revista Nacional de Educación, 28 (1942): 57-58. 
educacionales para los seglares deben conformarse con las legítimas disposiciones de la autoridad civil $\rangle^{90}$.

En fin, la Revista Nacional de Educación cooperó para dotar al régimen de una doctrina que luego pudiera concretarse en proyectos políticos. Este vínculo entre idea y acción está explícito en los editoriales de la revista y se plasmó, además, en muchas colaboraciones. El contexto de la revista ayuda a entender esta intención doctrinal en boga. Cinco días más tarde de que Ibáñez Martín hubiera pedido su colaboración a Laín Entralgo para el primer número, este le escribió para invitarle a participar en otra publicación: la revista Escorial ${ }^{91}$.

\section{HisPanidad y CUltura (1945-1951)}

En enero de 1945, la Revista Nacional de Educación empieza una segunda etapa más informativa. El editorial de la revista justificaba un mayor interés por la información «porque ha aumentado la labor ministerial digna de ser recogida $»^{92}$. Apenas un mes antes había salido a concurso la edición de la revista con una tirada de dos mil ejemplares ${ }^{93}$. En esta nueva etapa nacen secciones como «El quehacer y los días» y «Claros varones de España». Las noticias artísticas pueden leerse en «Del color, de la forma y de la farsa».

A partir de 1946, la publicación se desinfla, aunque ya el año anterior publicó tan solo nueve números ${ }^{94}$. Por otro lado, da la impresión de convertirse en desordenada revista cultural, con secciones que son más bien cajones de sastre y artículos diversos que continúan o no líneas de trabajo anteriores. Por ejemplo, un artículo José Rogerio Sánchez sobre Francisco de Vitoria y otro de Lillo Rodelgo sobre Baltasar Gracián ${ }^{95}$ seguían la tradición de artículos que indagaban en la historia de España para encontrar una pedagogía nacional.

Una razón de esta decadencia puede ser la deficiente gestión económica, circunstancia que conocemos por una carta posterior de Pedro Rocamora a Ibáñez

${ }^{90}$ Sancho, Silvestre (O. P.), «La educación cristiana a la luz de la 'Divini illius magistri'», Revista Nacional de Educación, 28 (1942): 45.

${ }^{91}$ Carta de Laín Entralgo, Pedro a Ibáñez Martín, José, 23/09/1940, AGUN, 139, 19.

92 «Editorial», Revista Nacional de Educación, 49 (1950): 7.

93 BOE, 343 (8 de diciembre de 1944): 9303.

${ }^{44}$ La publicación fue así: 1941 (doce números), 1942 (doce números), 1943 (diez números, dos de ellos dobles); 1944 (nueve números, tres de ellos dobles), 1945 (nueve números), 1946 (diez números), 1947 (ocho números), 1948 (ocho números), 1949 (nueve números), 1950 (siete números), 1951 (cuatro números).

95 Rogerio Sánchez, José, «El magisterio de Francisco de Vitoria», Revista Nacional de Educación, 60 (1946): 18-27. Lillo Rodelgo, José, «Baltasar Gracián o la voluntad», Revista Nacional de Educación, 64 (1946): 19-45. 
Martín en la que reconocía que la revista había presentado en 1947 un aspecto decrépito. En la carta, Rocamora se defendía de las críticas de un funcionario apellidado Díaz, Interventor de Hacienda en el Ministerio de Educación Nacional. Díaz había conseguido que la Revista Nacional de Educación se convirtiera en Organismo autónomo y, por lo tanto, dependiente de Hacienda. El director de la revista explicaba que Díaz había «colocado» en la redacción a sus dos hijos, que no habían acudido a trabajar, aunque además del sueldo normal habían percibido más de 50.000 pesetas en concepto de horas extraordinarias. En el tiempo en el que había gestionado la revista, hasta 1949, Díaz habría propuesto a Rocamora participar en diversos «timos» y maniobras e incluso había intentado inmiscuirse en la gestión del Ateneo de Madrid y el Colegio Mayor Ximénez de Cisneros, dirigidos por él ${ }^{96}$.

Pero la propaganda sobrevivió en la revista, en la que fue patente la evolución ideológica del régimen desde el tono azul falangista hasta una postura más neutral, consecuencia de la derrota del modelo político fascista en la Segunda Guerra Mundial y la necesidad de legitimarse de cara a los vencedores. En la política española se abrió paso un sector más definidamente católico encabezado por el nuevo ministro de Asuntos Exteriores, Alberto Martín-Artajo, nombrado en julio de 1945. En paralelo al relevo «católico» en el Gobierno, las competencias de la Vicesecretaría de Educación Popular del Partido (Prensa, Propaganda, Radiodifusión, Cinematografía y Teatro) fueron transferidas al Ministerio de Educación. Una de estas nuevas direcciones generales, la de Propaganda, recae en Pedro Rocamora, que va a poder desarrollar más completamente la «política del espíritu» en la que trabajaba su revista. No fue un ascenso extraño, pues parte de su labor al frente de la Revista Nacional de Educación fue, en la acepción más noble del término, de propaganda. En cualquier caso, de difusión de los principios y actividades del Ministerio de Educación Nacional. $\mathrm{Y}$ en determinados momentos, de los distintos intereses políticos, con sus correspondientes sistemas de ideas, que convivían (no siempre bien avenidos) en el régimen de Franco.

A partir de 1946, la propaganda legitimadora de la labor de España ganó terreno a los editoriales de política educativa de la revista. El Ministerio de Educación Nacional había recibido los medios de comunicación en un momento en que «la dimensión cultural acentuaría su protagonismo a consecuencia del ostracismo internacional que hubo de afrontar el régimen franquista desde finales de 1946»»' ${ }^{97}$. Las noticias que podía proporcionar el Ministerio de Educación eran muy susceptibles de convertirse en propaganda.

96 Carta de Rocamora, Pedro a Ibáñez Martín, José, 26/01/1949, AGUN, 139, 415.

97 Véase DELGADO GÓMEZ-ESCALONILLA, 1992: 457. 


\section{El Ateneo de Madrid y la causa hispanoamericanista}

En 1946, el Ateneo de Madrid, denominado en la posguerra Aula de Cultura, recobró su antiguo nombre y, aunque bajo la forma de organismo autónomo, fue adscrito a la Dirección General de Propaganda. A su vez, el director general, Pedro Rocamora, fue nombrado su presidente, posición que aprovechó para coordinar su trabajo. Así, el Ateneo se convirtió en lo que años después un editorial de la Revista Nacional de Educación denominó con ironía triunfal «peligroso foco de cultura» ${ }^{98}$. El Ateneo era un símbolo de la cultura liberal criticada por el nuevo régimen, pero, cómo explicó otro editorial, se había convertido en un lugar «purificado» por las nuevas ideas. Podía entonces recuperarse ese nombre simbólico de una institución que en su biblioteca había acogido - recordaba la revista - a personas que habían consagrado su tiempo «estudiando un programa de oposiciones o preparando una cátedra para servir después a España» ${ }^{99}$.

La Revista Nacional de Educación recogió en sus crónicas diversos actos ateneístas ${ }^{100}$ y publicó como artículos conferencias que fueron pronunciando allí hombres de la talla de José Ortega y Gasset, José María Pemán o José Larraz $^{101}$. Una de las maniobras sobresalientes de Rocamora al frente del Ateneo fue precisamente invitar a Ortega a que volviera a España, situación que se preveía muy útil a efectos de propaganda en el exterior ${ }^{102}$. En las crónicas también se aprecia la visita de figuras extranjeras como André Maurois ${ }^{103} \mathrm{o}$ Gabriel

98 «Editorial», Revista Nacional de Educación, 86 (1949): 8.

99 «Editorial», Revista Nacional de Educación, 60 (1946): 6. La misma idea puede leerse en la noticia «Nuevo perfil del Ateneo», Revista Nacional de Educación, 60 (1946): 59-60.

100 Véase, por ejemplo, los siguientes artículos: «Conferencias de Ortega y Gasset», Revista Nacional de Educación, 60 (1946). «Pemán, en el Ateneo de Madrid», Revista Nacional de Educación, 66 (1946). «El doctor Jiménez Díaz inaugura el curso en el Ateneo de Madrid», Revista Nacional de Educación, 74 (1947). «Nuevo curso de conferencias [inaugurado por Gregorio Marañón] en el Ateneo de Madrid», Revista Nacional de Educación, 93 (1950). «Gabriel Marcel inaugura el curso del Ateneo de Madrid», Revista Nacional de Educación, 99 (1950).

101 Véase Ortega y Gasset, José, «Idea del teatro», Revista Nacional de Educación, 62 (1946). Pemán, José María, «De la cuarta y definitiva salida de don Quijote de la Mancha», Revista Nacional de Educación, 68 (1947). Larraz, José, «La crisis de la sociedad contemporánea», Revista Nacional de Educación, 69 (1947).

102 Véase OLMOS, 2018: 460-463. Otro ilustre invitado de Rocamora fue Ramón Gómez de la Serna, al que la revista dedicó un editorial con motivo de su regreso a España: Revista Nacional de Educación, 85 (1949): 5-9. De la Serna colaboró en la revista con un artículo: «Supremacías de Quevedo», Revista Nacional de Educación, 85 (1949): 9-17. Véase también OLMOS, 2018: 513-514.

103 Maurois colaboró más tarde en la revista con «Esencia y existencia», Revista Nacional de Educación, 93 (1950): 9-15. Sobre su visita al Ateneo, véase "André Maurois en el Ateneo», Revista Nacional de Educación, 86 (1949): 95-99. 
Marcel, acontecimientos que, como expresaba un editorial de la revista, servían para demostrar una España diferente a la caricaturizada por la propaganda «enemiga». El Ateneo de Madrid desempeñaba así una labor hospitalaria y legitimadora ${ }^{104}$.

Como lugar de encuentro cultural, ya fuera entre extranjeros o los propios socios, el Ateneo servía para reforzar las ideas sobre las que España pretendía sentar una posición en el mundo. Los editoriales de la revista que aludían al Ateneo afirmaban a España como valedor de los viejos principios europeos y fortín sólido ante la crisis cultural y política que atravesaba el mundo.

España, como un oasis en medio de las tormentas del mundo, se esfuerza gozosamente por salvar su historia que, dígase lo que se quiera, es la cultura de Europa ${ }^{105}$.

La Revista Nacional de Educación registró esta actividad con repercusión política. En alguna ocasión la revista llegó a parecer un boletín del Ateneo, como en aquel editorial en el que, además de describir sus conferencias y el estado de la biblioteca, anunciaba la compra de una casa para ampliar sus instalaciones y agradecía el apoyo que le prestaba el Ministerio de Educación Nacional ${ }^{106}$. En otro editorial, se calificaba sin rubor al Ateneo como «la cátedra intelectual más popular de España» ${ }^{107}$.

Con motivo de la Feria del Libro de 1945, la Revista Nacional de Educación había destacado un dato: «El español, idioma de 100.000.000 de seres» ${ }^{108}$. Aunque aislado, el régimen podía jugar en su política exterior esta carta cultural. La influencia del elemento «espiritual» se probó en aquellos Estados con los que España había tenido un pasado común, que sobrevivía en el idioma y la religión. Otro factor nada desdeñable fue la coincidencia ideológica con regímenes como el Portugal de Salazar o la Argentina de Perón. La Revista Nacional de Educación colaboró en esta política, aunque, con el objetivo de no extender este artículo, nos centraremos en su misión de altavoz de la labor hispanoamericanista del Ateneo de Madrid, favorecida por la simpatía que suscitaban en aquella región los dirigentes católicos españoles o la idea de «hermandad»

104 Véase «Editorial», Revista Nacional de Educación, 84 (1949): 7-8.

105 «Editorial», Revista Nacional de Educación, 86 (1949): 5.

106 Véase «Editorial», Revista Nacional de Educación, 100 (1951): 5-7. No se olvide tampoco su intención legitimadora. Este editorial es una copia del texto del epígrafe «Ateneo de Madrid» del libro Diez años de servicio a la cultura española (1939-1949) de José Ibáñez Martín (Magisterio Español, Madrid, 1950: 758-759), publicado para divulgar y justificar su labor al frente del Ministerio.

107 «Editorial», Revista Nacional de Educación, 103 (1951): 7.

108 Véase «El español, idioma de 100.000.000 de seres», Revista Nacional de Educación, 53 (1945): 46-48. 
manejada por el régimen ${ }^{109}$. Ya Manuel García Morente, en aquella apertura del curso académico 1942-1943 en la Universidad Central, había recordado que a americanos y españoles «nos aprieta en vínculo estrechísimo: la hispanidad, la esencia personal del caballero cristiano, la sustancia colectiva de una misma fe en el destino eterno y trascendente de las criaturas $\rangle^{110}$.

La Revista Nacional de Educación publicó las conferencias «Los dos corazones del Paraguay» de Román Escohotado y «Algunas cosas de América» de Víctor Haedo pronunciadas, respectivamente, en abril de 1947 y mayo de 1948. Escohotado, periodista, introdujo su conferencia con un cuento sobre un boticario de Oviedo que había emigrado a Cuba, donde se había enamorado y casado con una mujer cubana. Al morir ésta, quiso volver a su tierra asturiana para visitar la tumba de sus padres, fallecidos mientras hacía la vida del emigrante. Pero el boticario, que había sufrido de nostalgia en Cuba, la sufría también en España. Así que un día, con el corazón dividido, se embarcó otra vez hacia Hispanoamérica y murió de melancolía durante el viaje. Su cuerpo, arrojado al mar, desde entonces flotaba en el Atlántico, entre una y otra patria. El cuento sirvió a Escohotado para introducir un viaje que había hecho por Paraguay. Allí también había encontrado corazones divididos: dos corazones, el indio y el español. Sin embargo, allí también, en Asunción, había tenido la ocasión de contemplar cómo estos se unían para formar el todo soñado, el Paraguay que no había renunciado ni a su tradición española ni a la libertad nacional. Escohotado proponía una nueva mirada a las repúblicas de Hispanoamérica y a su momento de independencia, suceso que consideraba natural, propio de la vida de aquellos territorios, pero también de la fecundidad española ${ }^{111}$.

Otra conferencia hispanoamericanista fue la pronunciada entre ovaciones por el político uruguayo Eduardo Víctor Haedo en el Ateneo de Madrid. Haedo invitó a concretar el hispanoamericanismo con orientaciones políticas que superaran el mero intercambio de mercancías o la labor exclusivamente cultural. Su proyecto consistía en integrar de manera regional y continental a los territorios hispánicos. El político uruguayo proponía primero que las repúblicas americanas recuperaran la soberanía que les estaba siendo arrebatada por cárteles y monopolios extranjeros que les impedían aprovechar sus recursos. El bloque que propugnaba debía entenderse con los Estados Unidos, país que, si bien había desarrollado una política colonialista en toda América, era poderoso

109 Véase DELGADO GÓMEZ-ESCALONILLA, 1992: 459.

110 García Morente, Manuel, «Ideas para una filosofía de la Historia de España», Revista Nacional de Educación, 22 (1942): 100.

111 Escohotado, Román, «Los dos corazones del Paraguay», Revista Nacional de Educación, 72 (1947): 9-37. 
y al que se podía convencer de que se vería beneficiado del apoyo de este bloque hispánico ${ }^{112}$.

Haedo fue muy realista ante su público español. En este sentido, matizó mucho las habituales apelaciones a la cultura compartida entre España y sus viejos territorios: ni en Hispanoamérica el catolicismo era tan pujante ni cabía en ellos que se instalaran sistemas políticos y económicos «dirigistas» que no atendieran a la «opinión popular». Una y otra, llevaban un siglo de historia independiente, cada una con sus preocupaciones. Las mismas naciones que antaño habían sido España estaban ahora divididas y apenas se conocían. De hecho, afirmaba Haedo, el interés en Hispanoamérica por los asuntos de España era reciente, fruto de la Guerra Civil española. No obstante, quería que los españoles colaboraran para elaborar un sistema que respetara la religión, las reivindicaciones del pueblo en materia económica y social, y las libertades políticas ${ }^{113}$. Esta elaboración y el bloque hispanoamericano serían una alternativa al comunismo y al capitalismo, con sus correspondientes sistemas de valores. Los propios Estados Unidos debían fomentar esta unión.

Y luego, en el Mundo, no aspiramos a ser mejores que los demás. (...) Lo que queremos es deshacer de una vez el monólogo. El gran error de Alemania fue hacer de toda su empresa un trágico monólogo. El gran error del fascismo fue convertir el monólogo en un medio y un procedimiento para hacerse oír. El gran error de Rusia es, actualmente, no ser más que una gran monologuista que, por la razón o por la fuerza, a nadie oye y atropella a quien no cae en su órbita.

Estados Unidos debe evitar caer en el mismo error. Que oiga, que dialogue con quien tiene que dialogar. Los Estados Unidos no pueden tener mejor interlocutor que la comunidad hispanoamericana si quieren ser moralmente respaldados y pesar en los destinos universales. (Grandes aplausos) ${ }^{114}$.

La revista publicó también el mensaje radiado del ministro de Asuntos Exteriores, Alberto Martín-Artajo, con motivo del Día de la Raza. Martín-Artajo celebraba que se restablecieran las relaciones con Argentina y Bolivia y deseaba que, poco a poco, lo hicieran otras repúblicas americanas. El ministro de Asuntos Exteriores lo denominaba «el retorno a la verdad de España» ${ }^{115}$. En realidad, la vida en común de los pueblos hispánicos estaba más bien limitada

${ }^{112}$ Ya antes de que terminara la guerra, España procuró mantener una buena relación con los Estados Unidos por su influencia en América, su capacidad mediadora con el resto de potencias occidentales y, más adelante, su enfrentamiento con el comunismo, véase DELGADO GÓMEZ-ESCALONILLA, 1992: 402-403 y 409-410.

113 Véase Haedo, Eduardo Víctor, «Algunas cosas de América», Revista Nacional de Educación, 82 (1948): 32-45

${ }^{114}$ Haedo, Eduardo Víctor, «Algunas cosas de América», Revista Nacional de Educación, 82 (1948): 43.

115 «El mensaje de España al mundo hispánico», Revista Nacional de Educación, 74 (1947): 64. 
al terreno de la cultura, de ahí que Martín Artajo señalara en su discurso una serie de conmemoraciones del año 1947 (Cervantes, Hernán Cortés...), las del año venidero (Tirso de Molina, la conquista de Sevilla...) y reuniones como la Asamblea del Idioma en Madrid y la Asamblea Americanista de Sevilla ${ }^{116}$. Quizá por este límite de la convivencia al terreno de la cultura, en uno de sus editoriales de temática hispanoamericana la Revista Nacional de Educación hizo hincapié en que más sólido que cualquier tratado era el cimiento de la cultura. La relación «espiritual» entre los pueblos de la hispanidad poseía, explicaba el editorial, el principio más fuerte que pudiera desearse. Cabe pensar que el editorialista creyera sinceramente en ello, que no se tratara solo de una excusa, pero al mismo tiempo señala el alcance de la política exterior española.

Podrán disentir, de momento, las fórmulas políticas. Esto es incidente transitorio. Lo que importa, lo que vale, es la comunidad - la comunión, diríamos nosotros - de sentimientos afines, en orden al espíritu humano, a su perfección y permanencia, entre esos pueblos sobre límites y cortapisas territoriales ${ }^{117}$.

\section{RENOVADO INTERÉS POR EL EXTERIOR}

La Revista Nacional de Educación había publicado en varios números una sección de «Notas docentes del extranjero». Hasta abril de 1942, cuando se abrió a todas las referencias posibles, solo había recogido información de regímenes afines desde el punto de vista ideológico o que habían ayudado al bando nacional en la Guerra Civil. De esta primera etapa es, por ejemplo, el artículo de Tomás Romojaro sobre Alemania, país en el que constató que «por su esencia, la revolución nacionalsocialista [es] una revolución pedagógica y no podía dejar de serlo» ${ }^{118}$. La misma revista, a título editorial, había dejado sentado que incluso los intercambios científicos debían tener un sentido ideológico y concebirse como «quehacer misional» ${ }^{119}$.

Sin embargo, ya estos primeros artículos y los que vinieron a continuación, fueron recogiendo una copiosa variedad de datos y geografías que trascienden a la ideología del momento. A partir de abril de 1942, con periodicidad mensual en este año y más espaciada a partir de 1943, constituyeron una fuente informativa valiosa para los lectores interesados en cuestiones técnicas acerca

116 Véase «El mensaje de España al mundo hispánico», Revista Nacional de Educación, 74 (1947): 63-65.

117 «Editorial», Revista Nacional de Educación, 89 (1949): 7.

118 Romojaro, Tomás, «Orientación y sentido de la educación alemana», Revista Nacional de Educación, 4 (1941): 96. Sobre el tema, otra visión es la de Magariños, Antonio, «Formación de los mandos en Alemania», Revista Nacional de Educación, 11 (1941): 89-100.

119 «Editorial», Revista Nacional de Educación, 3 (1941): 3. 
de los distintos sistemas de enseñanza. En este mes de abril de 1942, por ejemplo, la revista publicó datos sobre el analfabetismo en América, completados en el número siguiente con datos de la Oficina de Educación de los Estados Unidos y cifras de población en edad escolar, escolarizada y gasto en educación. Este último número citado incluía también unas notas sintéticas sobre las universidades de los Estados Unidos, Japón, la India y la reforma universitaria en Eslovaquia ${ }^{120}$.

La sección desapareció en 1944 y hasta dos años más tarde la revista apenas publicó algunos artículos de tema internacional, en concreto, sobre la enseñanza en Inglaterra ${ }^{121}$. Este interés anglosajón, aparentemente irrelevante en la trayectoria del Ministerio, arroja, sin embargo, un contraste notable con la etapa inicial de la revista e invita a tener en cuenta su influencia en los pedagogos y maestros españoles. Además, la revista prestó también cobertura informativa a las iniciativas que en materia de enseñanza comenzaban a desarrollar las Naciones Unidas para asegurar la paz en la posguerra: véanse los artículos «La Cooperación Internacional en materia de educación», de José Royo (Vicesecretario del CSIC), «Misión y servicio de la Oficina Internacional de Educación»y «Lazos docentes internacionales» ${ }^{122}$.

Ya a partir del número 60, en 1946, nace la sección «Ventana al mundo», que fue una de las principales secciones hasta 1949. El apartado prestó, por un lado, una atención especial a los sistemas de enseñanza en Inglaterra, los Estados Unidos y, en menor grado, en Francia. Se acrecentaba el interés por el sistema de enseñanza y las instituciones (reformas, universidades, segunda enseñanza y colegios, exámenes) anglosajonas, pero también publicó textos de un autor que, bajo la firma P.C.H., dio noticia sobre la educación de los excombatientes en los Estados Unidos ${ }^{123}$ y defendió en un par de sencillos artículos divulgativos la enseñanza progresiva ${ }^{124}$. Quizá resulte ilustrativo, como sín-

120 «Notas docentes del extranjero», Revista Nacional de Educación, 16 (1942): 103-108; «Notas universitarias del extranjero», Revista Nacional de Educación, 17 (1942): 65-80.

${ }^{121}$ Por ejemplo, «El estudiante de ciencias en una universidad inglesa», «Instrucción de los ingenieros de Gran Bretaña» o «Las modernas universidades británicas», Revista Nacional de Educación, números 54-58 (1945). La revista también reseñó una conferencia del agregado cultural de los Estados Unidos en la Universidad Central, Revista Nacional de Educación, 58 (1945) y un trabajo suyo sobre la organización de las universidades en EE. UU., Revista Nacional de Educación, 53 (1946).

122 Véase Royo, José, «La Cooperación Internacional materia de educación», Revista Nacional de Educación, 57 (1945): 21-27. Snowden, John, «Misión y servicio de la Oficina Internacional de Educación», Revista Nacional de Educación, 57 (1945): 67-70. «Lazos docentes internacionales», Revista Nacional de Educación, 68 (1946): 91-93.

${ }_{123}$ P.C.H., «Orientación educativa de la post-guerra», Revista Nacional de Educación, 62 (1946): 71-74.

${ }^{124}$ P.C.H., «La enseñanza progresiva en los Estados Unidos», Revista Nacional de Educación, 60 (1946): 71-75. P.C.H., «La polémica sobre la enseñanza progresiva en Inglaterra» [el 
toma de una relativa tolerancia, que explicara que ésta «arraigó en los Estados Unidos a fines del siglo pasado, gracias a la labor de hombres tales como Francis Parker y John Dewey, quienes consideraban que una democracia debía ser la cuna natural de la enseñanza progresiva. Los hechos parecen haber demostrado la razón de sus convicciones» ${ }^{125}$.

En otra línea, conectada con la política ministerial, destaca su cobertura, sobre todo propagandística, de la enseñanza y cultura hispanoamericanas; y de las visitas de artistas y científicos a la España de Franco (en 1947, por ejemplo, Dulce María Loynaz, Alfonso Junco y Roque Esteban Scarpa), alguno de ellos premiados con el ingreso en la Orden de Alfonso X el Sabio y, como ya se ha visto, conectados con el Ateneo de Madrid. Este esfuerzo podría entenderse mejor con un estudio detallado del apoyo del Ministerio de Educación Nacional al Instituto de Cultura Hispánica. Aunque no desapareció hasta 1951, la sección «Ventana al mundo» empezó a declinar a partir de 1949, cuando, además, solo prestaba atención a temas de índole exclusivamente cultural y artística. Este año, sin embargo, informó acerca de reuniones significativas celebradas en España: el I Congreso Internacional de Pedagogía, el Congreso Hispanoamericano de Educación y las Conversaciones Católicas Internacionales de San Sebastián ${ }^{126}$.

\section{Conclusiones}

En fin, la Revista Nacional de Educación fue un exponente de la política desarrollada por José Ibáñez Martín al frente del Ministerio de Educación Nacional (1939-1951). Durante diez años, la revista colaboró en el amplio cometido encomendado a Ibáñez Martín, que no se limitó a la gestión o reforma del sistema educativo, ni a alimentar doctrinalmente al régimen, sino que creó nuevas instituciones y, sobre todo a partir de 1945, se ocupó a través de la Subsecretaría de Educación Popular de gran parte de la cultura española, especialmente decisiva en la coyuntura difícil que atraviesa España al terminar la Segunda Guerra Mundial.

En este tiempo, se creyó que el Estado debía asumir la dirección de la política educativa y cultural, destinada a salvaguardar su integridad, pero también a obtener frutos espirituales. En cambio, no siempre hubo un acuerdo unánime acerca de cómo debía hacerlo. En la revista fue patente la pluralidad de la coalición autoritaria vencedora en la guerra civil española. Este artículo se detiene

título era erróneo, pues el autor hablaba de EEUU y no de Inglaterra], Revista Nacional de Educación, 69 (1947): 87-89.

125 P.C.H., «La enseñanza progresiva en los Estados Unidos», Revista Nacional de Educación, 60 (1946): 72-73.

126 Véase Revista Nacional de Educación, 89 (1949): 51-60, 87-96. 
en las limitaciones del sector falangista, que, en parte, encontró un escollo en la vieja cuestión de la libertad de enseñanza, fundamentada por Pío XI en la encíclica Divini Illius Magistri.

Pero debe quedar claro que, al igual que el ministro Ibáñez Martín, la Revista Nacional de Educación fue leal al general Franco. Con motivo de la fiesta del 18 de julio, Ibáñez Martín firmó un balance de su trabajo al frente del Ministerio de Educación en el editorial de la revista de julio de $1942^{127}$. En este texto, el ministro expresó su concepción de la política como servicio al Estado y lealtad a Franco. Ibáñez, que se mostraba satisfecho de su labor, hizo una defensa del ejercicio de la política como trabajo a largo plazo en el marco de lo posible. Como sabemos a posteriori, Ibáñez Martín, que no fue relevado hasta 1951, disfrutó de esta oportunidad del tiempo, incompatible con una actitud que no fuera la fidelidad al general Franco.

Pedro Rocamora, hombre de confianza de Ibáñez Martín, fue el encargado de dirigir la revista durante sus diez años de historia. La correspondencia revela un interés especial del ministro en ella, aunque la vida lánguida que arrastró a partir de 1946 también demuestra un progresivo apartamiento por la dedicación de ambos a otras tareas. En el caso de Rocamora, en 1946 fue nombrado presidente del Ateneo de Madrid, una institución relevante del amplio ámbito abarcado por el Ministerio de Educación Nacional, que extendió su área de influencia bajo la jefatura de Ibáñez Martín.

La Revista Nacional de Educación empleó géneros diversos (el editorial, la noticia, la crónica, el ensayo) para conseguir su objetivo cultural y divulgador. $\mathrm{Su}$ estudio ha demostrado que es una fuente significativa para conocer la España de los años 40, pero fue también un instrumento en manos del Gobierno y un apoyo intelectual a la política de Ibáñez Martín, hecho reflejado en los textos acerca de la reforma de la universidad. Las noticias acerca del Consejo Superior de Investigaciones Científicas, prolongadas durante diez años, así como las noticias del exterior, prueban también el talante informativo y propagandístico de la revista, que abarcó el conjunto del sistema de enseñanza.

\section{Bibliografía}

Alfonso Sánchez, José Manuel, Iglesia y Estado. La actuación de la Iglesia Católica en la legislación educativa española: Leyes de Enseñanza Media de 1938 y 1953, Madrid, Fundación Universitaria Española, 1993.

Delgado Gómez-Escalonilla, Lorenzo, Imperio de papel. Acción cultural y política exterior durante el primer franquismo, Madrid, CSIC, 1992.

127 Véase Ibáñez Martín, José, «Meditación política: el día 18 de julio», Revista Nacional de Educación, 19 (1942): 3-6.

Hispania, 2021, vol. LXXXI, n. ${ }^{\circ}$ 269, septiembre-diciembre, págs. 713-741, ISSN: 0018-2141, e-ISSN: 1988-8368 https://doi.org/10.3989/hispania.2021.018 
Ferrary, Álvaro, El franquismo, minorías políticas y conflictos ideológicos (19361956), Pamplona, Eunsa, 1993.

González Roldán, Gregorio, El proceso legislativo de la Ley de Ordenación Universitaria de 29 de julio de 1943, I y II, memoria de licenciatura inédita, Madrid, Facultad de Geografía e Historia de la UNED, 1985.

Ibáñez Martín, José, Diez años de servicio a la cultura española (1939-1949), Madrid, Magisterio Español, 1950.

Jerez, Miguel, «La Revista Nacional de Educación (1941-1945)», Las fuentes ideológicas de un régimen (España, 1939-1945), Zaragoza, Libros Pórtico, 1978: 177-210.

Olmos, Víctor, Agora de Libertad. Historia del Ateneo de Madrid, II (1923-1962), Sevilla, Ulises, 2018.

Pérez López, Pablo, «José María Albareda en los comienzos del Consejo Superior de Investigaciones Científicas (1939-1949)» en Francisco Javier Caspistegui e Ignacio Peiró (eds.), Jesús Longares Alonso, el maestro que sabía escuchar, Pamplona, Eunsa, 2016: 203-229.

Redondo Gálvez, Gonzalo, Política, cultura y sociedad en la España de Franco (19391975). I, Pamplona, Eunsa, 1999.

Revista Nacional de Educación, 1-103, Madrid, Ministerio de Educación Nacional, 1941-1951.

Saorín Pérez, Tomás y Blasco Gil, Yolanda, «Universidad e Hispanidad. Tres décadas de trayectorias entrecruzadas del ministro José Ibáñez Martín y el catedrático exiliado Mariano Ruiz-Funes», Revista de Indias, LXXVII/269 (Madrid, 2017): 263304.

Tusell, Javier, Franco y los católicos. La política interior española entre 1945 y 1957, Madrid, Alianza Editorial, 1984.

Recibido: 1/07/2019

Aceptado: 29/09/2020 